University of Nebraska - Lincoln

DigitalCommons@University of Nebraska - Lincoln

2020

\title{
The perceptions of AAC professionals on supporting the clinical translation of brain-computer interface technology
}

\author{
Kevin Pitt \\ University of Nebraska-Lincoln, kevin.pitt@unl.edu \\ Miechelle L. McKelvey \\ University of Nebraska at Kearney, mckelveyml@unk.edu \\ Kristy Weissling \\ University of Nebraska - Lincoln, kristy.weissling@unl.edu \\ Brynley Klein \\ University of Nebraska - Lincoln
}

Follow this and additional works at: https://digitalcommons.unl.edu/specedfacpub

Part of the Special Education and Teaching Commons

Pitt, Kevin; McKelvey, Miechelle L.; Weissling, Kristy; and Klein, Brynley, "The perceptions of AAC professionals on supporting the clinical translation of brain-computer interface technology" (2020). Special Education and Communication Disorders Faculty Publications. 215.

https://digitalcommons.unl.edu/specedfacpub/215

This Article is brought to you for free and open access by the Department of Special Education and Communication Disorders at DigitalCommons@University of Nebraska - Lincoln. It has been accepted for inclusion in Special Education and Communication Disorders Faculty Publications by an authorized administrator of DigitalCommons@University of Nebraska - Lincoln. 
Pitt, K., McKelvey, M., Weissling, K \& Klein, B (2020). The Perceptions of AAC Professionals on Supporting the Clinical Translation of Brain-Computer Interface Technology. Poster accepted at the 2020 American Speech-Language-Hearing Association convention, San Diego, CA (convention cancelled). doi:10.32873/unl.dc.oth.004 https://doi.org/10.32873/unl.dc.oth.004

\title{
Title:
}

The perceptions of AAC professionals on supporting the clinical translation of brain-computer interface technology

Pitt, McKelvey, Weissling \& Klein

\begin{abstract}
:
Brain-Computer Interfaces (BCIs) provide access to augmentative and alternative communication devices by decoding an individual's neurological activity. However, while BCI developments are progressing in the research setting, barriers still exist in the clinical setting. These must be overcome to support the successful translation of BCI technology into clinical practice which improves patient outcomes. Therefore, to help facilitate the clinical integration of BCI-AAC, our study sought to identify the perspectives of AAC professionals regarding their expectations for $\mathrm{BCI}$ technology and identify barriers and solutions for clinical translation.
\end{abstract}

\section{Introduction:}

Brain-Computer Interfaces may support augmentative and alternative communication device access (BCI-AAC) for those with severe physical impairments due to diagnosis such as Amyotrophic Lateral Sclerosis and Cerebral Palsy. BCI-AAC technology does not require an individual to possess a reliable form of physical motor control for AAC access. Therefore, BCI technology may provide alternative access for those who find existing access methods (e.g., switch scanning, eye gaze) inefficient, ineffective, or fatiguing (Brumberg et al., 2018). BCI$\mathrm{AAC}$ techniques overcome the physical barriers associated with existing AAC access methods by translating target neurological signals into communication device control. Specifically, BCI techniques target a variety of brain signals associated with sensory and motor processes that are utilized to control communication devices (see Brumberg et al., 2018 for review). For instance, P300-event related potentials are utilized as an established BCI signal (Donchin et al., 2000). To make a communication selection using the P300-BCI the individual attends to the target communication item (e.g., letter or symbol) they wish to select, while all other non-target items in the BCI-AAC display are randomly highlighted. Approximately 300 milliseconds (ms) after the individual's desired item (target stimulus) is highlighted, a positive voltage is detectable in the EEG recordings for the target stimulus in comparison to the other non-target stimuli (Donchin et al., 2000). The BCI algorithm then selects the item that is associated with this P300 event (Pitt, et al., 2019).

American Speech-Language Hearing Association (ASHA) policies for AAC practice emphasize the consideration of person-centered factors to comprehensively evaluate, respect, and 
support an individual's unique sensory-motor-language profile and cultural-linguistic diversity; providing access to a range of AAC systems/methods (e.g., ASHA 2004). However, thus far, the majority of BCI research is aimed at developing signal processing algorithms to identify the target $\mathrm{BCI}$ signal amongst environmental noise, rather evaluating how person-centered factors influence BCI outcomes (e.g., Chavarriaga et al., 2017). Therefore, while the development of effective $\mathrm{BCI}$ algorithms is crucial for improved $\mathrm{BCI}$ outcomes, there are still multiple gaps to address for BCI's successful integration with ASHA guidelines for clinical practice (Pitt, Brumberg \& Pitt, 2019). Therefore, to link BCI research to everyday clinical practice it is critical that the input of $\mathrm{AAC}$ professionals is incorporated into $\mathrm{BCI}$ research. Incorporating stakeholder perspectives can help ensure BCI advancements can fully build upon, and leverage, existing AAC practices in supporting person centered BCI development (Pitt, Brumberg, \& Pitt, 2019). However, to date, there has been limited incorporation of the perspectives of clinically-based $\mathrm{AAC}$ specialists and professionals in $\mathrm{BCI}$ research. Therefore, through this study we aim to bridge the gap between laboratory based BCI research and clinical application by identifying the perspectives of AAC professionals including their expectations for BCI technology, barriers to implementation, and possible solutions for clinical translation.

\section{Procedure:}

Five speech-language pathologists (SLPs) certified in clinical competency (CCC) with a minimum of two years' experience in AAC (mean of 18.2 year's AAC experience, range 8-30 years, SD 9.94) completed a semi-structured interview to identify SLP perspectives along with barriers and solutions for BCI translation. All participants identified themselves as clinical AAC specialists. All of the interviews were audio recorded and transcribed verbatim, including language features such as laughing and pausing, by a trained graduate assistant. After initial transcription, a second graduate assistant checked transcription accuracy, with discrepancies discussed until reaching consensus. Following transcription, files were imported into NVIVO software for analysis. Using a grounded theory/data driven approach (Gibbs, 2008), interview themes were grouped using NVIVOs coding features to identify similarities in participant responses. Themes were identified via $100 \%$ consensus between all authors.

\section{Results:}

Data collection and analysis is ongoing at the time of proposal. Preliminary results indicate that $4 / 5$ interviewed SLPs foresee BCI potentially having a large impact on those who currently find traditional AAC access methods ineffective or inefficient. For instance, P5 reported, "Every day we can do better with our kids. And so, I just feel like if something better is out there, you should at least give the opportunity to try it. You can't work in technology and not think that tomorrow there's gonna be something better. There always has been". Primary themes noted regarding current barriers to BCI translation include; funding and insurance coverage (noted by $4 / 5$ participants), apprehension around high technology devices (noted by $3 / 5$ participants), a lack of clinical awareness (noted by $2 / 5$ participants), and that $\mathrm{BCI}$ is limited to literate adults (noted by $2 / 5$ participants). Primary solutions and future directions for $\mathrm{BCI}$ translation included: helping support BCI implementation (e.g., simple set up, stakeholder training; noted by $5 / 5$ participants), bringing $\mathrm{BCI}$ alongside existing $\mathrm{AAC}$ access methods and procedures (noted by $4 / 5$ participants), and making BCI research more relevant to clinicians by including a range of clinical populations (noted by $3 / 5$ participants). 


\section{Conclusion:}

Understanding the perspectives and needs of the individuals responsible for implementing AACBCI technology is crucial in supporting the clinical translation of BCI-AAC techniques (Pitt, Brumberg \& Pitt, 2019). This clinical translation will result in improved communication outcomes for people who are communicatively compromised. The continuous development and expansion of this work may help advance greater interest in AAC-BCI developments and foster multidisciplinary collaborations resulting in translation of BCI into clinical practice by helping align BCI research with existing ASHA policies for AAC practice.

\section{Learning Outcomes}

Attendees will be able to:

1) describe different BCI-AAC access methods

2) identify different barriers possibly hindering BCI translation

3) identify different solutions to support BCI translation.

\section{References}

Brumberg, J. S., Pitt, K. M., Mantie-Kozlowski, A., \& Burnison, J. D. (2018). Brain-computer interfaces for augmentative and alternative communication: A tutorial. American Journal of Speech-Language Pathology, 27(1), 1-12. https://doi.org/10.1044/2017_AJSLP-16-0244

Chavarriaga, R., Fried-Oken, M., Kleih, S., Lotte, F., \& Scherer, R. (2017). Heading for new shores! Overcoming pitfalls in BCI design. Brain-Computer Interfaces, 4(1-2), 60-73.

Donchin, E., Spencer, K. M., \& Wijesinghe, R. (2000). The mental prosthesis: assessing the speed of a P300-based brain-computer interface. IEEE transactions on rehabilitation engineering, 8(2), 174-179.

Gibbs, G. (2008), Analyzing Qualitative Data. London: Sage Publications

Pitt, K. M., Brumberg, J. S., Burnison, J. D., Mehta, J., \& Kidwai, J. (2019). Behind the scenes of noninvasive brain-computer interfaces: A review of electroencephalography signals, how they are recorded, and why they matter. Perspectives: ASHA Special Interests Groups, 4(6), $1622-1636$.

Pitt, K. M., Brumberg, J. S., \& Pitt, A. R. (2019). Considering augmentative and alternative communication research for brain-computer interface practice. Assistive Technology Outcomes and Benefits, 13(Summer), 1-20. 
